\title{
KÕNETAJU KATEGORIAALSUS EHK HÜPOTEES SELLEST, KUIDAS ME KEELELISI ÜKSUSI TAJUME
}

\author{
Nele Salveste \\ Tartu Ülikool
}

\begin{abstract}
Kokkuvõte. Erinevate häälikute laad meie igapäevases kõnes varieerub tugevalt, kuid häälduse varieeruvus ei ole enamasti kõneeristusele takistuseks. See annab alust oletada, et kõnetaju on välja arendanud süsteemi, millega tuvastada foneeme väga suure varieeruvusega kõnesignaalist. See süsteem tegeleb kõne varieeruvusega nii tõhusalt ja kiiresti, et me ei ole sellest enamasti teadlikud. Seda süsteemi võiks nimetada kategoriaalseks tajuks (ingl Categorical Perception), kuid kuna taju on uurimisele üksnes kaudselt kättesaadav, siis tähistab see termin pigem eksperimentaalset mudelit või meetodit, millega uuritakse taju võimet foneeme kõnesignaalist eristada. (Schouten jt 2003) Käesolevas artiklis arutatakse kategoriaalse taju kui mudeli ja katsemeetodi üle, mille teoreetilised lähtekohad on olnud nii muudes keeltes kui eesti keeles läbi viidud tajukatsete ülesehituse ja järelduste eeldusteks.
\end{abstract}

Märksõnad: kategoriaalne taju, identifikatsioonikatse, diskriminatsioonikatse, välde, foneetiline varieerumine kõnetajus

\section{Sissejuhatus}

Kujutagem endale ette situatsiooni, kus kaks head meesterahvast sõpra arutlevad avameelselt kooli, abielu ning laste kasvatamise ning harimise üle ning üks nendib siis järsku, et sõber, kelle abikaasa juhtub parasjagu ka kooliõpetaja olema, on ikka paras tahvlialune küll. Sõber, kelle kohta seda öeldi, mõtleb pikalt järele: sõbra lausungis kõlas küll justnagu „tahvli”, aga see ei tundu loogiline, sõna sobib käsitletud teemade ringi, aga sellist väljendit ei ole ta varem kuulnud. Jah, küllap ütles sõber ikkagi „tuhvlialune”. See olukord esitab meile sisuliselt kaks küsimust. Esiteks: mis võis esimese sõbra häälduses veidi teisiti olla kui 
muidu? Ning teiseks: kuidas jõudis teine sõber ikkagi õige sõna äratundmiseni?

Esimesele küsimusele on lihtne vastata. Sõbra kommentaaris kõlas vokaal $u$ rohkem hääliku $a$ sarnaselt. Ilmselt mõjutas siin $h$ artikulatsioonikoht vokaali $a$ hääldamist, nõnda et huuled jäid veidi avatuks ning keel ei asunud nii kõrgel kui täiskvaliteedilise $u$ moodustamisel. See tähendab, et kõneelundid valmistasid end juba $u$ hääldamisel ette $h$ hääldamiseks ning selle tõttu kõlas $u$ tugevalt $a$ sarnasena. Mida on aga sellest situatsioonist õppida kõnest arusaamise kohta? Kuulaja kasutab enamasti kõne mõistmiseks kogu vestlussituatsioonis kättesaadavat informatsiooni, mis hõlmab näiteks konteksti, kollokatsioone, sõnasagedusi, fonotaktikat ning veel palju muud. Ülaltoodud situatsioonis toetas kõneleja taotletud sõna äratundmist ilmselt kõige tugevamalt öeldu idiomaatilisus.

Erinevate häälikute laad meie igapäevases häälduses varieerub tugevalt, kuid häälduse varieeruvus ei ole tänu ülalnimetatud kontekstuaalsetele teguritele enamasti kõneeristusele takistuseks. Sissejuhatuseks toodud olukord pakub aga tajuuurijale huvi just nimelt seetõttu, et vestluse sisu toetas tugevalt ka sõna tahvli taju. Siin on küsimuseks, missugused akustilised nähtused toetavad ühe või teise keeleüksuse mõistmist situatsioonides, kus muu situatsioonist kättesaadav informatsioon ei ole enam ühemõtteline. Säärased olukorrad on ka lugejale ilmselt igapäevaelust tuttavad.

Seda, missugused häälikute foneetilised tunnused määravad häälikutaju, on uuritud kategoriaalse taju (ingl Categorical Perception) uurimisparadigma raamides. Alates 1950ndatest aastatest on kirjanduses lähtutud sellest, et kategoriaalne taju on nähtus, mis seletab taju võimet tuvastada foneeme väga suure varieeruvusega kõnesignaalist. Kuna aga taju on uurimisele üksnes kaudselt kättesaadav, siis Bert Schouten jt (2003) soovitavad selle mõistega tähistada pigem eksperimentaalset mudelit või meetodit, millega uuritakse taju võimet erinevaid foneeme kõnesignaalist eristada ning tuvastatakse keeleliste kategooriate piire määravaid akustilisi tunnuseid. Käesoleva artikli eesmärk on tutvustada klassikalist kategoriaalse taju mudelit 
ning katsemeetodit, näidata, kuidas on kategoriaalse taju mudeli teoreetilised lähtekohad seotud paljude eesti keele jaoks läbi viidud tajukatsetega ning vaadelda, missugused uurimisküsimused pakuvad kategoriaalse taju uurimisparadigma raames huvi.

\section{Kõnetaju}

Selleks, et mõista, mida taju üldse kõnesignaalist eristama peab, tuleks lisaks sellele, kuidas kõneelundid töötavad, mõista ka seda, missugused nähtused on seotud erinevate häälikute akustikaga. Igasugune heli koosneb erinevate sagedustega osahelidest. Meie häälekurrud tekitavad võnkudes põhitooni, mis on kõnesignaali madalaima sagedusega osaheli, ning põhitooniga suhestatud ülemtoonid. Kui häälekurdude tekitatud heli läbib kõnetrakti, siis vastavalt kõnetrakti muutuvale kujule ühed osahelid summutatakse ning teised võimendatakse ning tekivad formandid ehk kõnetrakti resonantsiõõntes võimendunud helispektri sagedusribad. See, kuidas formantide sagedused ajas muutuvad, iseloomustab erinevaid häälikuid ning annab neile nende kvaliteedi.

Vokaalide heliline omadus tuleneb häälekurdude võnkumisest tekkinud põhitooni olemasolust ning seetõttu on formandid just vokaalide ja heliliste konsonantide olulisteks tunnusteks. Helitute konsonantide puhul häälekurrud ei võngu ning konsonandi kvaliteedi määravad helisignaalis formantide siirded konsonandilt vokaalile. See ühtlasi tähendab, et helitud konsonandid on tajutavad üksnes klusiil-vokaal-järgnevustes. Joonis 1 illustreerib formantide siirdeid, mis annavad inglise helilise konsonandi $d$ taju erinevate vokaalide ees (Liberman jt 1967). Joonisel on toodud esimese ja teise formantide (F1, F2) siirded konsonandilt vokaalile. Näeme, et sõltuvalt sellest, kas siire vokaalile tõuseb või langeb muutub ka vokaali kvaliteet $i$-st $u$-ks. Samuti on siirete kaugus teineteisest määrav: kui $i$ puhul asuvad F1 ja F2 teineteisest väga kaugel, siis $a$ puhul asuvad nad hästi lähestikku. 


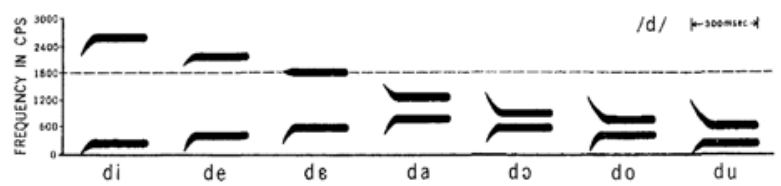

Joonis 1. Esimese ja teise formandi siirded konsonandilt $d$ vokaalile erinevate vokaalide ees (Liberman jt 1967).

Niisiis, mida tähendab taju kategoriaalsus? Taju kategoriaalsus viitab taju omadusele tajuda füüsikalist pidevat ruumi üksteisest eraldatud piiritletud üksustena. See on universaalne nähtus ning ei ole omane pelgalt keeletajule. Eksperimentaalselt on tõestatud, et taju kategoriaalsus on näiteks iseloomulik värvide (Davidoff jt 1999) ning näoilmete tajule (Etcoff, Magee 1992). Seda nähtust illustreerib joonis 2.

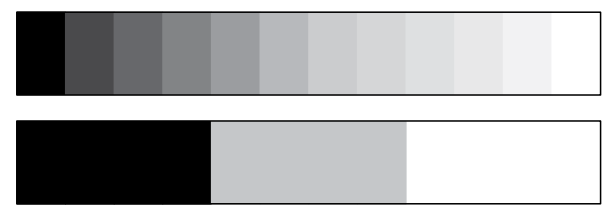

Joonis 2. Ülemisel real värvipalett toonidega, mis varieeruvad mustast hallini, alumisel real värvipalett, milles ülemise rea toonid on jagatud kolme kategooriasse: must, hall, valge.

Joonise 2 ülemisel real muutuvad toonid sujuvalt mustast halliks ning hallist valgeks. See on n-ö füüsikaline sidus reaalsus, kus värvipalett ei jagune piiritletud üksusteks. Teatud tingimustes aga, kus meil ei ole tervet 12-liikmelist toonide rida käepärast, jagab meie taju need erinevad toonid kolmeks kategooriaks: mustaks, halliks ning valgeks, nagu joonise 2 alumisel real näha.

Joonise 2 ülemine rida esitleb musta-valge füüsikalise kontiinumi. Kõne puhul on võimalik leida samasugune füüsikaline kontiinum formantide jaoks. Alvin Liberman ja tema kolleegid (1957) sünteesisid 14 stiimulit, milles esimese formandi siirded jäeti muutmata ning teise formandi siirdeid muudeti samm-sammult, nagu näha joonisel 3. 


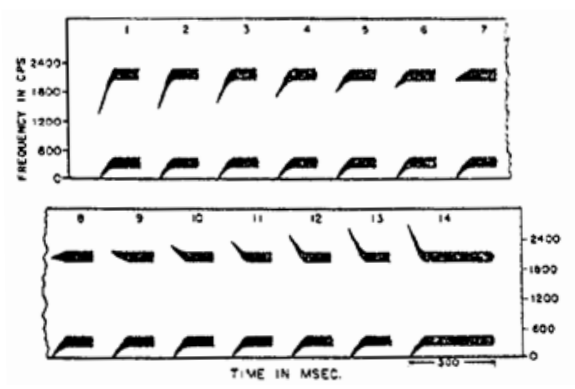

Joonis 3. 14 konsonant-vokaal-stiimulit, milles teise formandi siire konsonandilt vokaalile muutub samm-sammult (Liberman jt 1957).

Joonisel 3 on näha, et teise formandi siire muutub sammsammult tõusvast siirdest laskuvaks siirdeks. Liberman ja kolleegid lasid keelejuhtidel nõnda sünteesitud konsonante kuulata ning öelda, kas nad kuulevad silpi be, de või ge. 14 konsonanti esitati keelejuhtidele juhuslikus järjekorras, nii et kontiinum ei olnud neile kättesaadav. Nagu demonstreerib joonis 4, jagasid keelejuhid need 14 kontiinumi elementi kolme diskreetsesse kategooriasse: be, de, ge.

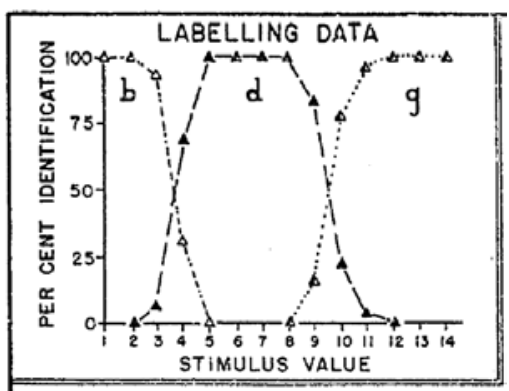

Joonis 4. Keelejuhtide $b, d$ ja $g$ vastuste protsent identifikatsioonikatses (Liberman 1957), y-teljel vastuste protsent, $\mathrm{x}$-teljel 14 stiimulit kontiinumina (vt joonis 3).

Joonisel 4 on näha, et kui teise formandi siirded tõusevad, siis tajutakse konsonanti $b$, kui teise formandi siirde tõus 
on väike või see ei muutugi, siis tajutakse konsonanti $d$, ning kui teise formandi sagedus hakkab langema, siis tajutakse konsonanti g. Ehk, katse tulemusena jagasid keelejuhid formantkontiinumi kolmeks diskreetseks kategooriaks. Tegelikkuses on aga näiteks konsonandi $d$ akustiline representatsioon veidi keerulisem, nagu jooniselt 1 välja lugeda võis. Seal nägime, et erinevate vokaalide puhul on ka formandisiirded erinevad. Seega peab meie tajumehhanism olema kõnesignaalist häälikute tuvastamisel veelgi nutikam, kui Libermani ja tema kolleegide katse (1957) näidata püüdis.

\section{Kategoriaalne taju kui katsemeetod}

Nagu eelpool juba viidatud, lähtuvad Schouten jt (2003) eelkõige sellest, et kategoriaalne taju on pigem teoreetiline mudel ja katsemeetod ning et see ei peegelda täielikult seda, millised keelelised üksused või kategooriad tegelikult keelekasutaja peas eksisteerivad. Kategoriaalse taju mudeli keeleliste kategooriate tuvastamiseks tajus kehtestasid Liberman ja tema kolleegid oma 1957. a artiklis. Mudeli juurde kuulub eksperimentaalne metoodika, mis koosneb kahest katsest, mis enamasti toimuvad (kuid ei pruugi toimuda) allolevas järjekorras:

1) identifikatsioonikatse: katseisikule esitatakse kontiinumisse kuuluvad stiimulid juhuslikus järjekorras ning tal tuleb need klassifitseerida ühte või teise katse läbiviija poolt ette antud kategooriasse;

2) diskriminatsioonikatse: katseisikule esitatakse stiimuleid omavahel kombineerituna ning tal tuleb üles leida erinev stiimul. Meetodi selles osas on suurel määral erinevaid katsemeetodeid välja töötatud ja järele proovitud, nagu näiteks $\mathrm{ABX}, \mathrm{AXB}, \mathrm{AX}, 4 \mathrm{IAX}{ }^{1}$, kus $\mathrm{X}$ on varieeruv stiimul, mille

1 4IAX ehk kahe stiimulipaari diskriminatsioon (ingl dual pair discrimination), milles katseisikule esitatakse kaks paari stiimuleid nõnda, et ühes paaris on mõlemad stiimulid ühesugused ning teises paaris erinevad. Katseisikul tuleb öelda, kumb paar oli erinev. 
kohta tuleb keelejuhil vastata, kas see on stiimulitest A või B erinev või mitte (vt Repp 1984: 265-267).

Kategoriaalse taju mudel esitab 4 tingimust, mille kehtimine määrab, kas stiimulid kuuluvad vastavate akustiliste tunnuste alusel erinevatesse kategooriatesse või mitte:

1) identifikatsiooni funktsiooni kurv on kategooria piiril järsu langusega; üleminek ühest kategooriast teise on järsk;

2) diskriminatsiooni funktsiooni tipp asub kategooria piiril; stiimuleid eristatakse paremini siis, kui nad langevad üks ühele ja teine teisele poole kategooria piiri;

3) ühte kategooriasse kuuluvaid stiimuleid eristatakse halvasti; diskriminatsiooni ulatus on 50\% või vähem (Liberman jt 1957, 1967);

4) diskriminatsiooni funktsioon on identifikatsiooni funktsioonist ennustatav: identifikatsioonikurvi langus langeb kokku diskriminatsioonikurvi tipuga (Liberman jt 1957, Repp 1984: 252-253). Identifikatsiooni- ning diskriminatsioonikurvide omavaheline seos on kujutatud joonisel 5 .

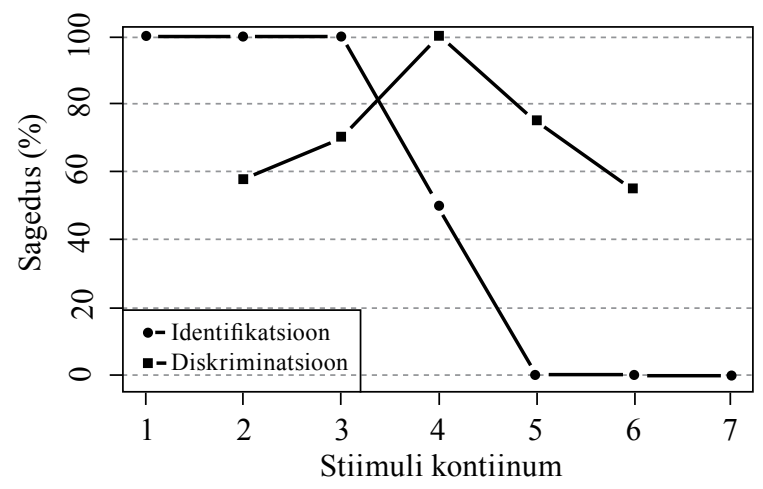

Joonis 5. Kategoriaalse taju hüpoteesitud ideaalne korrelatsioon identifikatsiooni- ja diskriminatsioonikurvide vahel.

Kategoriaalse taju kui meetodi puudus seisneb selles, et katsetulemused annavad harva joonisel 5 toodud ja katsemeetodi poolt nõutud ideaalseid identifikatsiooni- ja diskriminatsiooni- 
kurve, ning seetõttu saab rakendada vaid ühte või kahte kriteeriumit stiimulite kategoriaalsuse määramiseks. Selles mõttes oleks ehk põhjust rääkida pigem taju kategoriaalsuse erinevatest astmetest, nagu on pakkunud Bruno Repp (1984: 252).

Katsed kategoriaalse taju mudeli raamides on näidanud, et klusiilid ning vokaalid käituvad tajus erinevalt. Konsonante tajutakse erinevate katsete raamides tugevalt kategoriaalsetena, mis tähendab, et ühele ja teisele poole kategooriapiiri jäävaid stiimuleid tajutakse erinevatena, kuid kategooria sees olevaid stiimuleid samasugustena. Vokaalide tajus sellist efekti ei ole leitud. Vokaalide puhul on keelejuhid võimelised eristama ka kategooriasiseseid erinevusi. (Liberman 1967) Schouten jt (2003) on näidanud, et tegelikult on ka klusiilide tugev kategoriaalsus kaheldav ning katseisikud on võimelised eristama ka kategooriasiseseid erinevusi. Nii et see, kas ja milliseid häälikuid või keelelisi üksuseid tajutakse kategoriaalsetena, on tegelikult siiani uuritav ja vaieldav küsimus (vt nt Shouten jt 2003, Gerrits ja Shouten 2004).

\section{Kategoriaalse kõnetaju kui teoreetilise mudeli olulised uurimistulemused}

Alates Libermani ja tema kolleegide avaldatud katsetest ja katsetulemustest 50ndatel aastatel on aga taju kategoriaalsusest kujunenud üldiselt aktsepteeritud teoreetiline mudel, millega seletatakse arvukate kõnetajukatsete tulemusi. Eelpool kirjeldatud katsemeetodiga on püütud ja püütakse senini tõestada erinevate tajuteooriate kehtimist.

Otse kategoriaalse taju sünnihällist pärinevad modulaarse kõnetaju ideed (Liberman jt 1967, Liberman ja Mattingly 1985), mis väidavad, et meie tajus eksisteerivad erinevad moodulid keelelise ja mittekeelelise akustilise informatsiooni töötlemiseks. Samamoodi toetuvad kõnetaju kategoriaalsusele eksemplaarse kõnetaju mudelid (Stevens 1972, 2005), mis sedastavad, et lingvistilised üksused on kõnetajus suuremad kui foneem ning et need lingvistilised üksused on seostatud akustilistest tun- 
nustest koosnevate šabloonidega. Need šabloonid hõlmavad aga tunduvalt rohkem erinevaid akustilisi nähtusi, kui vaid näiteks formante või formandisiirdeid. Sisuliselt väidavad eksemplaarse kõnetaju teooriad, et inimese ajus on salvestatud ja ligipääsetav kogu akustiline informatsioon lingvistiliste üksuste kohta. Taju kategoriaalsusest lähtuvad ka viimatised statistilised tajumudelid (Feldman jt 2009, Clayards jt 2008), mis tõestavad, et tajus eksisteerivad kategooriaid määravate akustiliste tunnuste jaotused, mida on võimalik uue keelelise sisendi kaudu manipuleerida ning mille alusel taju ennustab ühe või teise kategooria olemasolu kõnesignaalis. Keeleteoorias ennustatakse kategoriaalse taju mudeliga kategooriapiiride tekkimist ning seletatakse ja põhjendatakse tihti fonoloogiliste kategooriate olemasolu.

Eesti keeles on kategoriaalse taju mudelist pärineva katsemeetodiga uuritud vokaalide ja konsonantide eristamist üldkeeleteaduslike vokaali- ja konsonanditaju andmete valguses. Arvo Eek ja Einar Meister $(1994,1996)$ on uurinud eestlastest keelejuhtide häälikutaju samm-sammult muudetud formandisageduste või formandisiiretega. Eek ja Meister (1994) määratlevad eesti vokaalide tajuruumi piirid ning näitavad, et kui vokaalikategooriad ei eristu akustilisel hertsides esitatud vokaalidiagrammil piisavalt hästi, siis barkidesse arvutatud vokaalidiagramm hoiab vokaalikategooriad üksteisest selgelt lahus ning need peegeldavad ka tajuandmeid. Samamoodi hoiab vokaalikategooriaid lahus ka kaalutud teise formandi (F2') väärtus. Eek ja Meister (1996) tõestavad, et keelejuhid on küll võimelised tuvastama formandisiirete abil konsonantide kvaliteete, kuid kasutavad konsonantide eristamisel ilmselt siiski kogu spektraalset informatsiooni. Lya Meistrilt (2009) pärineb võrdlev uurimus eesti keelt kõnelevate vene emakeelega keelejuhtide ja eesti keelt emakeelena rääkivate keelejuhtide eesti keele vokaalide kategooriapiiridest. Võõr- ja emakeelsete häälikukategooriapiiride lõikumispunktid nii kõneloomes kui kõnetajus on olnud kategoriaalse taju alases kirjanduses erilise tähelepanu all (Sumner 2011, Pineda ja Sumner 2010, Repp 1984: 310-316, vt ka viiteid Meister 2009). Kõrvutavad katsed võõrkeelsete keelekasutajatega toovad välja, missugused akustilised tunnused on kategoo- 
ria tekkimisel olulised ning missuguste prosoodiliste tunnuste poolest keeled erinevad. Katsed, milles treenitakse emakeelseid kuulajaid tajuma aktsendiga kõnet, võimaldavad demonstreerida kõnesituatsioonides pidevalt toimuvaid protsesse, nagu kõneleja kohandumine (ingl perceptual adaption) või omandamisefektid (ingl perceptual learning), mis peegeldavadki mõnes mõttes seda, kuidas keelekasutajad suudavad igapäevaselt tulla toime kõne suure foneetilise varieerumisega.

Eesti keele taju-uurimises on aga kõige enam tähelepanu pälvinud eesti keele häälikukestuste taju (Lehiste 1960, 1970-75, Eek 1980a, 1980b, Eek ja Meister 2003, Lippus jt 2007, 2009). Stiimulite langemist erinevatesse kategooriatesse on kasutatud väldete fonoloogilise iseloomu määratlemiseks. Tajukatsete kaudu on tõestatud, et eesti keeles ei ole mitte neli, vaid kolm väldet (Lehiste 1997, Eek 1980b), et välde ei ole mitte hääliku või silbi, vaid kõnetakti omadus (Eek 1980a, Eek, Meister 2003), ning et välde realiseerub eeskätt esimese ja teise silbi kestussuhtena kõnetaktis (Lehiste 1960, Eek 1980a). Kõige enam on vältetaju-alases kirjanduses saanud tähelepanu põhitoon (Lehiste 1960, 1970-75, Eek 1980b, Lippus jt 2007, 2011), sest on sedastatud, et ilma langeva intonatsioonita teist väldet kolmandast vältest eristada ei suudeta (Lehiste 1997). Pärtel Lippus jt (2009) on näidanud, et erinevalt teise emakeelega keelejuhtidest, kasutavad eesti emakeelega keelejuhid väldete eristamiseks olulisel määral põhitooni.

Vältetaju katsetes on stiimulite kontiinumid olnud veidi keerulisemad, kui on olnud häälikute puhul, kuna eksperimenteeritud on häälikust suuremate üksustega ning kontrolli all on tulnud hoida rohkem nähtusi kui ühe formandi siire. Peamiselt on hoitud kontrolli all kestust ja põhitooni. Katsete jaoks on samm-sammult häälikute kestusi kas kasvatatud või kahandatud, põhitoonikontuuri on aga mingil määral originaalilähedasena hoitud (Eek 1980a, Lippus jt 2007). Põhitooni olulisust vältetajus on testitud erinevatest meloodiakontuuridest koosnevate kontiinumitega, nagu on toodud näiteks joonisel 6 (Salveste 2010). Joonisel 6 on esitatud 6 meloodiakontuuri, millest esimese (tähistatud numbriga 1) puhul asub see koht, kus põhitoon 
nö pöördub ja langema hakkab vokaali alguses, kolmanda puhul kuskil vokaali keskel ning kuuenda puhul peaaegu et vokaali ja konsonandi piiril. Ilse Lehiste (1970-75) hoiab oma stiimulites kontrolli all nii häälikute kestusi kui põhitooni. Nendes katsetes on keelejuhtidel tulnud öelda, mis vältes nad ühte või teist stiimulit kuulevad. Analoogselt Libermani ja tema kolleegide katsetega on katseisikud suutnud määrata, kas kuuldud stiimul kuulub esimesse, teise või kolmandasse vältesse. Nõnda on tõestatud kestussuhete või põhitooni olulisust vältekategooriate tajus ning vajadust nendega fonoloogias tegeleda.

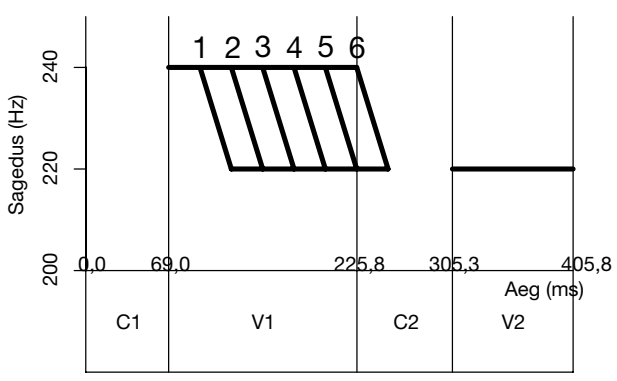

Joonis 6. Kuus erinevat põhitoonikontuuri kahesilbilisest kõnetaktist koosnevas stiimulis $(\mathrm{C}=$ konsonant, $\mathrm{V}=$ vokaal, y-teljel sagedus (Hz), x-teljel aeg (ms)).

Liberman jt (1967) avasid oma artiklis kategoriaalse taju paradigma raames kõnetaju üldisi omadusi puudutava suure küsimuste ringi. Akustilised mõõtmised on näidanud, et kõnesignaal on väga varieeruv. Ei ole võimalik leida akustilist tunnust, nagu näiteks teise formandi siire, mis eristaks seotud kõnes üht konsonanti või vokaali teisest alati ühtemoodi. Kategoriaalse taju katsete raames on püütud tuvastada, missuguseid akustilisi tunnuseid kasutab kuulaja süstemaatiliselt oma sisemiste lingvistiliste kategooriate loomiseks. Diskriminatsiooni- ja identifikatsioonikatsete abil on selgitatud, kus tekivad n-ö füüsikalises sidusas ruumis kategooriate piirid ning missugused akustilised nähtused kõnesignaalis põhjustavad nende kategooriate tekke. Ehk siis, eesmärk on olnud leida, kus asuvad keeleüksuste inva- 
riantsed ehk mittevarieeruvad süstemaatilised tunnused. Liberman jt on pakkunud, et need on hääldusliigutustes (Liberman jt 1967, Liberman, Mattingly 1985). Kenneth N. Stevens (1972, 1989, 2005) on aga leidnud, et need peituvad ikkagi akustilises signaalis kogu spektraalse informatsiooni kombineerimises, millest paistab lähtuvat ka Eegi ja Meistri (1996) uurimus. Keith Johnson (2007) toetab hoopiski ideed, et invariantsus on leksikaalse tasandi omadus ning erinevad akustilised nähtused kõnesignaalis moodustavad n-ö tunnuste kimbud, mille abil kuulaja sõnamustreid tuvastab. Viimane on tõenäoliselt liiga lihtsustatud lähenemine. Dennis Norris jt (2003) näitavad, et ilmselt kasutab kuulaja ühtaegu nii teadmisi keelest kui konkreetsest akustilisest signaalist pärinevaid andmeid.

Just niisama varieeruvad, nagu on häälikute akustilised tunnused kõnesignaalis, paistavad olevat häälikukategooriate piirid ka meie tajus. Kuulajad on võimelised oma sisemisi kategooriaid vastavalt vajadusele avardama või kitsendama. Rikkaliku sissevaate sellesse pakuvad tajukatsed võõr- või murdeaktsendiga kõnest (Bradlow, Bent 2008, Sumner 2011, Pineda, Sumner 2010, Dahan jt 2008, Kraljic jt 2008). Norrise jt (2003) tajueksperiment pakub suurepärase vaatluse sellest, kuidas kuulaja on võimeline vastavalt keelelisele sisendile oma sisemisi kategooriaid kohandama. Norrise jt uurimuses treeniti kõigepealt katseisikuid kahes rühmas. Esimene rühm keelejuhte kuulis akustilises mõttes häälikute $f$ ja $s$ vahepeale jäävat stiimulit koos sõnadega, mille lõpus oli ainult $f$, ning teine rühm koos sõnadega, mille lõpus oli ainult $s$. Katse oluliseks tulemuseks oli, et treeningsituatsioonile järgnenud identifikatsioonikatse tulemused olid kahes rühmas erinevad: kui katseisikud kuulsid kahemõttelist stiimulit koos $f$-sõnadega, siis sai stiimul rohkem $f$-vastuseid ning kui katseisikud kuulsid seda stiimulit koos $s$-sõnadega, siis nad andsid rohkem $s$-vastuseid. Norrise jt (2003) katse näitab, et leksikaalse konteksti toel on võimalik häälikukategooriate piire tajus nihutada. Artiklis esitletakse tajumudel, mis sedastab, et selline õppimine ei ole võimalik pelgalt leksikaalse tasandi ehk ülevalt alla tagasisidemehhanismina, vaid sinna peab olema kaasatud ka eelleksikaalne ehk alt 
üles tagasisidemehhanism. Laskumata sügavamalt sellesse teoreetilisse diskussiooni, võime sellest katsest aga järeldada, et varieeruvast kõnesignaalist arusaamine ei toetu vaid kontekstuaalsetele teguritele ja lingvistilistele teadmistele, vaid et kõnetaju tegeleb paralleelselt kõnesignaali akustilise analüüsiga ning on võimeline selle analüüsi tulemusena juba eksisteerivate kategooriate piire kas avardama või kitsendama. See, et lisaks häälduse varieerumisele on häälikukategooriate piirid ka tajus väga paindlikud, teebki meie kõneeristusvõime nõnda efektiivseks.

\section{Kokkuvõte}

Kokkuvõtteks võib öelda, et kategoriaalne taju võib tähistada kirjanduses sisuliselt kahte asja. Esmalt võib selle all mõista taju võimet eristada kõnesignaalist erinevaid keelelisi üksusi ning ühtlasi ka nähtust, kus füüsikalises mõttes sidus akustiline signaal jagatakse lingvistiliste teadmiste alusel diskreetseteks keelelisteks üksusteks, nagu näiteks häälikuteks või kõnetaktideks. Teiseks on kategoriaalne taju mudel, mille abil saab ennustada ning seletada kategooriapiiride tekkimist. Selle mudeli juurde kuulub ühtlasi identifikatsiooni- ning diskriminatsioonikatsest koosnev katsemeetod, mis seab katsetest saadud tulemuste tõlgendamisele ranged reeglid.

Käesoleva artikli eesmärk oli näidata, kuidas kategoriaalse taju mõiste on pakkunud võimaluse uurida, mismoodi kõnelejad-kuulajad tegelevad igapäevaselt häälduse suure varieeruvusega. Raske on öelda, kas kategoriaalne taju on pigem keelejuhi strateegia tulla toime eksperimentaalse situatsiooniga (Gerrits ja Schouten 2004) või eksisteerivad tõesti meie ajus erinevad keelelised kategooriad, millega on viidud vastavusse erinevad akustilised tunnused. Üle poole sajandi erinevaid katseid erinevate keeltega pakuvad keeletaju kohta siiski väga palju andmeid ning regulaarsus keelejuhtide reaktsioonides, sõltumata erinevatest katsesituatsioonidest, annab alust arvata, et kõnetaju kategoriaalsus on meie kõneeristuse baas. Siit edasi saab vaadelda, millised muutused akustilistes tunnustes kujun- 
davad kategooriate piire, missugune on taju kategooriate piiril ning kategooriate sees, mida ütlevad need andmed meie kõnetaju kohta üldiselt ning kuidas saame me nende andmete abil kõnetaju modelleerida.

Eesti keeles läbi viidud foneetilised katsed ei ole enamasti kasutanud tervet kategoriaalse taju mudelit koos selle juurde kuuluva katsemeetodiga, vaid on enamasti rakendanud identifikatsioonikatset (Lehiste 1960, Eek 1980a,b, Eek ja Meister 1994, 1996, Lippus jt 2007, 2009, 2011). Katsetulemuste tõlgendamisel on aga olnud oluline kategoriaalse taju uurimisparadigmast pärinev teoreetiline lähtekoht, et identifikatsioonikatsega on võimalik tuvastada akustiliste tunnuste alusel tekkivate keeleliste kategooriate piire ning tõestada nende eksisteerimist tajus.

\section{Tänuavaldused}

Artikli autor on äärmiselt kasulike ning õpetlike kommentaaride ja paranduste eest tänulik oma juhendajatele Pire Terasele ja Eva Liina Asu-Garcíale, artikli anonüümsele retsenseerijale ning armsatele kaasdoktorantidele Piia Taremaale ning Miina Norvikule. Autori õpingud ja uurimus on olulisel määral saanud toetust Eesti Teadusfondi allikatest GFLEE7904 ja GFLEE6983.

\section{Aadress:}

Nele Salveste

Eesti ja üldkeeleteaduse instituut

Tartu Ülikool

Jakobi 2

51014 Tartu

E-mail: Nele.Salveste@ut.ee 


\section{Kirjandus}

Bradlow, R. Ann, Tessa Bent (2008) "Perceptual adaptation to non-native speech". Cognition 106, 707-729.

Clayards, Meghan, Michael K. Tanenhaus, Richard N. Aslin, Robert A. Jacobs (2008) "Perception of speech reflects optimal use of probabilistic speech cues". Cognition 108, 804-809.

Dahan, Delphine, Sarah J. Drucker ja Rebecca A. Scarborough (2008) “Talker adaptation in speech perception: adjusting the signal or the representations?" Cognition 108, 710-718.

Davidoff, Jules, Ian Davies ja Debi Roberson (1999) "Colour categories in a stone-age tribe". Nature 398, 203-204.

Eek, Arvo (1980a) "Estonian quantity: notes on the perception of duration". In A. Eek, ed. Estonian papers in phonetics, 5-30. Tallinn: Academy of Sciences of the Estonian S.S.R.

Eek, Arvo (1980b) "Further information on the perception of Estonian quantity". A. Eek, ed. Estonian papers in phonetics, 31-57. Tallinn: Academy of Sciences of the Estonian S.S.R.

Eek, Arvo, Einar Meister (1994) „Eesti vokaalide sihtväärtused hääldus- ja tajuruumis". Keel ja Kirjandus 7, 404-413, 8, 476-483, 9, 548-553.

Eek, Arvo, Einar Meister (1996) „Eesti sõnaalguliste sulghäälikute akustika ja tajumine”. Keel ja Kirjandus, 3, 164-170, 4, 241-253, 5, 314-321.

Eek, Arvo, Einar Meister (2003) „Foneetilisi katseid ja arutlusi kvantiteedi alalt (I). Häälikukestusi muutvad kontekstid ja välde”. Keel ja Kirjandus 11, 815-837, 12, 904-918.

Etcoff, Nancy L., J. John Magee (1992) "Categorical perception of facial expressions”. Cognition 44, 227-240.

Feldman, H. Naomi, Thomas L. Griffiths, James L. Morgan (2009) “The influence of categories on perception: explaining the perceptual magnet effect as optimal statistical inference". Psychological Review 116, 4, 752-782.

Gerrits, Ellen, Marten Egbertus, Hendri Schouten (2004) "Categorical perception depends on the discrimination task". Perception \& Psychophysics 66, 3, 363-376.

Johnson, Keith (2007) "Decisions and mechanisms in exemplar-based phonology". In M. J. Sole, P. Beddor, M. Ohala, eds. Experimental approaches to phonology: in honor of John Ohala, 25-40. Oxford: Oxford University Press.

Kraljic, Tanya, Susan E. Brennan, Arthur G. Samuel (2008) "Accommodating variation: dialects, idiolects, and speech processing". Cognition 107, 54-81.

Lehiste, Ilse (1960) "Segmental and syllabic quantity in Estonian”. In Thomas A. Sebeok, ed. American studies in Uralic linguistics, 21-82. (Uralic and Altaic Series, 1.) Bloomington: Indiana University Publications. 
Lehiste, Ilse (1970-1975) "Experiments with synthetic speech concerning quantity in Estonian". In Valmen Hallap, ed. Congressus Tertius Internationalis Fenno-Ugristarum, Tallinae habitus, 17-23. VIII 1970. Pars I: Acta Linguistica, 254-269. Tallinn: Valgus.

Lehiste, Ilse (1997) "Search for phonetic correlates in Estonian prosody". In I. Lehiste, J. Ross, eds. Estonian prosody: papers from a symposium, 11-35. Tallinn: Institute of Estonian Language.

Liberman, Alvin M., Katherine Safford Harris, Howard S. Hoffman, Belver C. Griffith (1957) "The discrimination of speech sounds within and across phoneme boundaries". Journal of Experimental Psychology $54,5,358-368$.

Liberman, Alvin M., Franklin S. Cooper, Katherine Safford Harris, Peter F. MacNeilage, Michael Studdert-Kennedy (1967) "Perception of the speech code". Psychological Review 74, 431-461.

Liberman, Alvin M., Ignatius G. Mattingly (1985) "The motor theory of speech perception revised". Cognition 21, 1, 1-36.

Lippus, Pärtel, Karl Pajusalu, Jüri Allik (2007) "The tonal component in perception of the Estonian quantity". The Proceedings of the 16th International Congress of Phonetic Sciences, Saarbrücken, 6-10 August 2007, 1049-1052. <http://www.icphs2007.de/conference/ Papers/1029/1029.pdf> Vaadatud 29.10.2012.

Lippus, Pärtel, Karl Pajusalu, Jüri Allik (2009) "The tonal component of Estonian quantity in native and non-native perception". Journal of Phonetics 37, 388-396.

Lippus, Pärtel, Karl Pajusalu, Jüri Allik (2011) "The role of the pitch cue in the perception of the Estonian long quantity". In S. Frota, G. Elodieta, P. Prieto, eds. Prosodic categories: production, perception and comprehension, 231-242. Dordrecht, Heidelberg, London, New York: Springer.

Meister, Lya (2009) „Eesti vokaalikategooriate piirid vene ja eesti emakeelega kõnelejate tajuruumis". Eesti Rakenduslingvistika Ühingu aastaraamat = Estonian Papers in Applied Linguistics 5, 143-156.

Norris, Dennis, James M. Queen, Anne Cutler (2003) "Perceptual learning in speech". Cognitive Psychology 47, 2, 204-238.

Pineda, Marisa, Meghan Sumner (2010) "A distributional analysis of VOT in French-accented English”. Ettekanne konverentsil „159th Annual Meeting of the Acoustical Society of America", Baltimore, MD. $<$ http://www.stanford.edu/ middyp/media/non-native-vot-asa-2010. pdf $>$ Vaadatud 29.10.2012.

Repp, Bruno H. (1984) “Categorical Perception: issues, methods, findings”. In Norman J. Lass, ed. Speech and language: advances in basic research and practice 10, 243-335. Orlando: Academic Press.

Salveste, Nele (2010) "Variation of pitch cues in the perception of quantities". In S. Werner, T. Kinnunen, eds. XXVI Fonetiikan päivät 2010, Soome, Mekrijärve, 25.-26.02.2010. University of Eastern Finland, <http:// 
epublications.uef.fi/pub/urn_isbn_978-952-61-0391-4/urn_isbn_978952-61-0391-4.pdf $>$ Vaadatud 29.10.2012..

Schouten, Bert, Ellen Gerrits, Arjan van Hessen (2003) "The end of categorical perception as we know it". Speech Communication 41, 71-80.

Stevens, Kenneth Noble (1972) "The quantal nature of speech: evidence from articulatory-acoustic data”. In Edward E. David ja Peter B. Denes, eds. Human communication: a unified view, 51-66. New York: McGrawHill.

Stevens, Kenneth Noble (1989) "On the quantal theory of speech". Journal of Phonetics 17, 3-45.

Stevens, Kenneth Noble (2005) "Features in speech perception and lexical access". D. B. Pisoni, R. E. Remez, eds. The handbook of speech perception, 125-154. Malden, Oxford, Carlton: Blackwell Publishing Ltd.

Sumner, Meghan (2011) "The role of variation in the perception of accented speech". Cognition 119, 1, 131-136.

\begin{abstract}
Nele Salveste: Categorical perception or the hypothesis of how we perceive linguistic units. The acoustic signal of everyday speech is very variable, but it seldom distracts the normal speech communication. This motivates the hypothesis that the speech perception must have developed a special mechanism for extracting phonemes from highly variable speech signal. This mechanism extracts phonemes so efficiently and quickly that we are often unaware of it. We would like to call this mechanism "categorical perception of speech", but since the perceptual processes are only indirectly accessible for investigation, the term refers rather to a theoretical model or an experimental method for investigating our perceptual ability to distinguish phonemes from the speech signal so efficiently (Schouten et al. 2003). In this paper the Categorical Perception as an experimental method and its theoretical statements will be discussed in connection to perception experiments and findings in other languages as well as in Estonian language.
\end{abstract}

Keywords: categorical perception, identification experiment, discrimination experiment, Estonian quantities, phonetic variation in speech perception 